Such knowledge can and should be better utilized for predicting pest and natural enemy development and behavior and for purposes of manipulating climatic conditions for the detriment of pests and the benefit of natural enemies to encourage pesticide-free production in both organic and integrated production greenhouses.

Examples on the effect of greenhouse climate on pests and their natural enemies:

- Thrips are killed in crop clean-up by raising temperature above $40{ }^{\circ} \mathrm{C}$ and keeping humidity very low for $1-3$ days

- Raising temperature by $4-5{ }^{\circ} \mathrm{C}$ for $3 \mathrm{~h}$ increases pesticide efficacy against thrips due to increased flight activity of the pest.

- Parasitoid Eretmocerus eremicus performs better than Encarsia formosa against whiteflies in low light levels in the winter.

- Elevated $\mathrm{CO}_{2}$ levels and continuous lighting halve the fecundity of the greenhouse whitefly (Trialeurodes vaporariorum).

- $\quad$ UV-B wavelengths given in non-phytotoxic dosages for max. 5 min. every third night keep powdery mildew, a fungal disease of plants, in control.

- The infective units (conidia) of Isaria fumosoroseus, a fungus that kills insects, persist better on wet foliage and on foliage submitted to wetting-drying cycles, than on dry foliage.

\section{Future Research}

By knowing better how pests and natural enemies respond to climatic conditions two things become possible for enhanced plant protection:

- manipulation of the greenhouse climate not only for the benefit of plants, but also for natural enemies.

- improving predictions on the population development of pests and natural enemies.

With improved predictions, it becomes easier to know more exactly when to make decisions regarding extra release of natural enemies, doing chemical backup treatments, or knowing how elevated $\mathrm{CO}_{2}$ or other factors slow down pest population development and help in controlling them. All this, however, requires that we gain more information on pest and disease biology in conditions of semi-closed or closed greenhouses, fluctuating and distributed temperature conditions and under different lighting regimes and technologies. Climate-based prediction models and warning systems that aid in plant disease management pave way for such developments also for arthropods so that coupling climate-based plant models with pest and natural enemy population models becomes part of greenhouse crop protection practice. Several research needs to reach these goals can be discerned:

1) Development of climate-based population models for pest and beneficial arthropods and plant disease agents this requires studies of key pests' temperature, light and humidity responses.

2) Coupling climate-based plant models with those of pest and natural enemy biology and behavior to see which approach is more feasible, considering that the crop always comes first: manipulating the climate or predicting the development of pests and beneficials and acting better upon such predictions for pest management.

3) Performance of key pests and biocontrol agents in climate conditions created for the sake of energy efficiency and reduction of humidity and temperature problems: closed and semi-closed greenhouses, greenhouses with cladding materials creating diffused lighting conditions, fluctuating temperature regimes, specific light spectra for plant growth and defense, and for manipulating biology and behavior of pests and beneficial organisms.

4) Early warning and decision support systems (DSS) for prognosis and timing of control treatments for more pathogen and arthropod pest species.

5) Implementation of climate-based population models in practical greenhouse growing.

6) LED-lights can be used to control certain pathogens with specific wavelengths, but not all pathogens respond similarly. Integrating LED-based technologies in crop production regimes requires careful studies in order not to benefit some pest species while controlling others.

7) Specific wavelengths used for attracting and trapping pests and manipulating daily rhythms with specific wavelengths to disrupt arthropod life cycles.

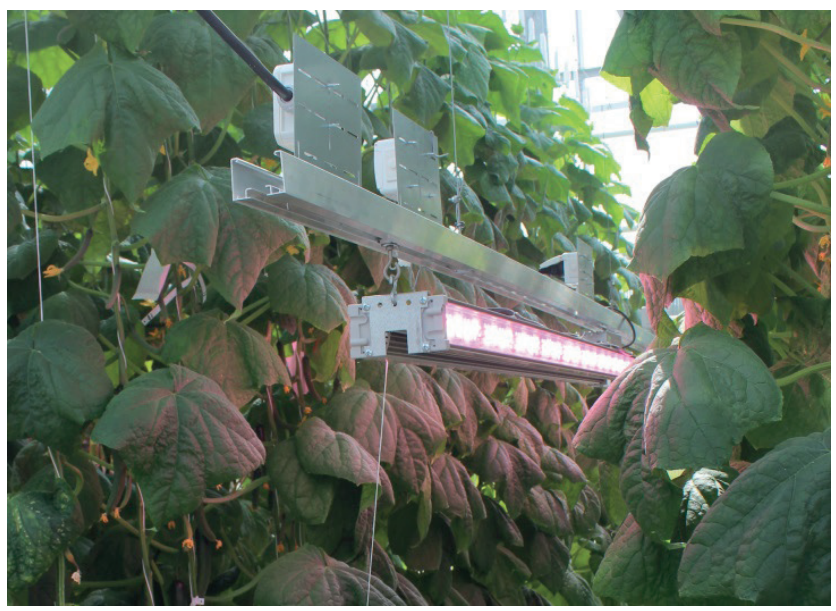

Figure 2. LED-lightning in a greenhouse cucumber crop.

References: Johansen, N. s., Vänninen, I., Pinto, D. m., Nissinen, A. i., Shipp, L., 2011. In the light of new greenhouse technologies: 2. Direct effects of artificial lighting on arthropods and integrated pest management in greenhouse crops. Ann. Appl. Biol. 159, 1-27.

Acknowledgement: This work was supported by COST Action FA1105 "Towards a sustainable and productive EU organic greenhouse horticulture".

DOI: http://dx.doi.org/10.18174/373604

Author: Irene Vänninen

Affiliation: Natural Resources Institute Finland (Luke)

Contact: Irene.Vanninen@luke.fi

Authors of the figures: Irene Vänninen

January 2016 